\title{
Cartooning Humor: How Arabs are Laughably Derided in Animations
}

KOME - An International Journal of Pure Communication Inquiry Volume 3 Issue 2, p. 64-74.

(C) The Author(s) 2015

Reprints and Permission: kome@komejournal.com

Published by the Hungarian Communication Studies Association DOI: 10.17646/KOME.2015.25

\section{Mohamed Belamghari}

Mohammed First University, Morocco

\begin{abstract}
Some animated movies use humor to capture the full attention of its audience. In so doing, the movie's messages have become a great concern for many theorists and critics by virtue of the idea that a movie can be a repository of ideologies meant to construct a certain type of easy-going and noncritical audience. This paper, therefore, takes the example of Max Fleischer's Popeye the Sailor Meets Ali Baba and his Forty Thieves (1937) and Robert Clampett's Ali Baba Bound (1941) as its case studies aiming at spotting the different manifestations of humor, taking Arabs as its subject-matter, becoming a leaked ideology and taming the discourse that is amplified, manipulated, and delivered to the Western public in unwarrantable ways compared to the imagery of Westerners.
\end{abstract}

Keywords: Passive/silent spectatorship, Humor, Anachronism, Ideology, Stereotypes

The bleak visions of quite a few novels of the period are couched in a bitterly irreverent humor that has the capacity to shock readers out of their apathy and self-pity; to produce an angry laughter that is hopefully more productive than despair; to disorient in order to reorient. (Al-Nowaihi 2005: 295)

It has often been remarked that part of the philosophy of humor is to draw unexpected results from unexpected situations. It can often be noticed in some novels or films that what should not be laughed at becomes, though, the butt of the joke. In a movie, for instance, one would notice that sometimes the oppressed or weak gets laughed at (which is contrary to what normally people should do: empathize with the weak) and is thus made to seem to deserve what happens to him or her and be the butt of the movie's joke. Readers or spectators, this way, are oriented to adhere to the ideologies of humor and are shocked out of their apathy. 
Quite dexterous in many animated movies about Arabs is the way in which humor is utilized quick-wittedly with the purpose of leaking ideological messages to spectators.

In this respect, this article deals with the complicated and controversial issue of humor in relation to ideological manipulations. By drawing particularly on two Hollywood cartoons, Max Fleischer's Popeye the Sailor Meets Ali Baba and his Forty Thieves (1937) and Robert Clampett's Ali Baba Bound (1941), this mental enterprise is bent on analyzing how these short films construct a comically ideological view of Arab life. This is to say that such types of movies not only encourage spectators to totally drown in a state of reverie, and thus absorb all is transmitted without questioning, but also, through comical humor in animated films, cartoon producers tend to amplify the implementation of stereotypic, anachronistic, and anecdotal features of Arabs, which could also have long-term destructive consequences to both Arabs and Westerners.

Indeed, Media provide the possibilities, in various forms, for entertaining spectators, particularly through the genre of comical humor presented in animated films. Having engaged in such an entertaining enterprise, Media, in this regard, has provided an outlet for film producers to rally as big a number of audience as their films can entice so as to make significant profits. At this stage, profit has come to occupy the main interests of most film producers, and the attainment of such profits would require seeking attractive themes for their film production. Arabs would perfectly suit the moment by weaving romantic and stereotypical stories around them, exactly in conformity with the worn and torn fantasized imageries of The Arabian Nights. In so doing, some film producers have relied on film messages to manipulate the public and direct the course of actions in their countries to their advantage. There are, in fact, plenty of messages filtered through different media outlets that have helped best weave the schemes of movie producers in their quest to control the minds of the masses.

Such mind control, desired by movie producers, is conditioned to mesmerize spectators into believing every single idea and scene presented to them through TV screens. The idea is to let film ideologies flow, one after another, unnoticed and uncritical. The noticeable figure of spectators turns into devoted and almost uncritical admirers and applauders for all the movie's scenes or TV messages. They, accordingly, fail to realize when a scene can be ideological, becoming noncritical applauders who do not take the quest for content control against producers and, as a result, filmic ideologies have gone unnoticeable because of the overlaid humor. At this stage, we may find someone hysterically laughing at a character being comically beaten even though that same character is the oppressed and the one who should be commiserated. This is simply the case because it is widely believed that "for most of the audience, most of the time, the film is a form of escape" (Stevenson 2002: 88) from their habitual, dreary lives. In a nutshell, the film's audience "is rendered as virtual and univalent as the images which are being referred to" (Bignell 2000: 161). In such a context, the usage of humor in films becomes a hypnotizing tranquilizer serving the purpose of relieving people's problems. What matters more now is to laugh, not to think about the subject of the laughter. This is also a truism because, "these films seek no criticality from their audiences, there are no spaces invested by themselves for creative interpretation; instead these films seek a compliant investment of power from the individual" (Fuery \& Fuery 2003: 3-4). These types of movies are in fact more than just entertaining ones in the sense that they have gone beyond their initial entertaining and humorous functions and have been permeated with political and ideological propensities while becoming technically more sophisticated and aesthetically more attractive. 
In fact, reading the immense amount of discourse surrounding animated films, one might begin to think that some of those within the cartoon audience are forced into accepting and believing what they see on cable TV. They are now made to look like they are badly needing to be scolded into watching what is good for them (Curtis 1994). In view of that, "the [viewer] is 'positioned' ideologically; certain [cinematic] features 'determine' how the [viewer] will respond to the represented events or the depicted characters; viewers have no choice but to accept the ideological 'demands' of the narrative system" (Jenkins 1992: 64). This kind of disciplinary view of the movie has shaped an easy-going audience who only needed some so-called entertainment to absorb whatever ideology is in the air at any given period of time, (Curran \& Donelan 2009: 143) for, in fact, it can be argued that many people have enjoyed animated films not only because of their comic-based nature but also for the free and instant vicarious travel they have guaranteed.

The standard line about animated films has been that they have made travel available to everyone. Cartoons have been continually celebrated for having made it possible to experience other fantasy places without actually having to travel. In this mode of experiencing, "the world is laid out on a table to be viewed and classified by the viewer who can now hope to attain the position of God by viewing that world as a picture" (Gere 2010: 154). Importantly, such rhetoric of animated films assumes that the more fantastical and funny things are, the more excited and interested the audience will become. The spectators, be they children or adults, find animated films appealing because they have made it accessible for them to experience some place (any place) different, thereby enabling them to leave their current monotonous conditions. Like all desires, this relies on the drives of fantasy and humor more than anything else. Here lies the cartoon's appeal: it provides fantastical images molded humorously to fit the frame of culturally-determined exotic fantasies.

Clearly, the lure of the fantasy worlds being depicted comically is what brings spectators to cartoons. In such a context, different kinds of spectators have been shaped: the ones who enjoy the films thanks to the kinds of reverie they inspire, but not a spectator who watches in order to better educate him or herself. A cartoon film here, therefore, plays the role of transporting its viewers to the simulated world of televisual imagery, for it incessantly hypnotizes them into unquestionably absorbing the multitude of film images in a total state of reverie - for the notable theorist of reverie Gaston Bachelard (1969), reverie is "a flight from out of the real" (1969: 5). This situation has resulted in producing a passive/silent spectatorship cast into a state of reverie when they become part and parcel of the movie. What they see comes to constitute part of their daily lives. Their presence in the movie is elongated so that it can last as long as the movie is exhibited. This kind of motive has allowed spectators to happily daydream about different places and different ways of life. At this stage, the world as a whole "takes form in our reverie, and this world is ours. This dreamed world teaches us the possibilities for expanding our being within our universe" (1969: 8). In fact, one of a comic cartoon's primary appeals has been to offer a space apart for contemplating other possible visions of dwelling in the world, a quiet space for speculation and laughter, even if this is brought about through stereotypical conventions.

It should be noted that this reserved space of daydreaming that the cartoon offers seeks to construct an experience of a comic and quiet life by washing over the viewer and shutting out critical rationalization instead encouraging a reverential mental transportation cloaked in a humorous fashion. This transportation always leads to fossilizing stereotypes and ready-made judgments in the mind of spectators, thereby creating new realities and worlds for them to enjoy. In support of this, many scholars have viewed cartoons as participating in the act of 
producing reality instead of reflecting it. Following the same path, cartoons create new humorous realities and shape popular perceptions according to the society's structures of domination. According to this approach,

\begin{abstract}
The control of point-of-view is the most powerful means of inducing a kind of imaginary response on the part of the spectator, "positioning" the spectator by addressing the viewer through visual devices such as the point-of-view shot and shot/reverse-shot cutting in order to fashion a very tight bond between spectator and text. In this way, the text may be said to "inter-pellate" the spectator into the fictional world so that its values, and its ideology, become one with the viewing subject. (Stam et al. quoted in Persson 2003: 145)
\end{abstract}

In a nutshell, films not only reflect the world but also produce reality and shape public perceptions. Thus, some cartoons often promote stereotypical attitudes about a people being represented or made the subject matter of humor. Worse yet, such stereotyping has not gone without its ensuing devastating results in the sense that it vilified a people and made their descendants a target of numerous heinous attacks, especially in many different Western countries. This is the case mainly because films have exerted much of their power on their audiences' minds and turned them into apathetic, non-questioning, noncritical audiences who absorb any televisual content whatsoever. To account for this latter claim, suffice it to contend with the idea that some film producers, more than ever before, have targeted younger generations to implant the seeds of hatred and thus keep the wheel of animosity between East and West, as binary antagonistic entities, rolling from one generation to another. This also explains the reason why animated audiences are readily open to influences in media content more than any other type of audience.

In fact, targeting younger generations through ideological messages in films have had many different negative effects both on Arab and Western children. Unfortunately, the objectives of many cartoon movies are not just to educate, but also to instill hazardous and discriminatory views in the mind of Western children about others. Basically, children and young adults are socialized by the media to identify Arabs by the use of Orientalist stereotypes. The continuous circulation of these stereotypes from one generation to another will allow such derogatory images of Arabs and Muslims to exist in discourse. As a result, by five years of age,

\begin{abstract}
Many children have definite stereotypes about blacks, women, and other social groups. Children don't have a choice about accepting or rejecting these conceptions, since they're acquired well before they have their own cognitive abilities or experiences to form their own beliefs... they must compete with all the forces that would promote and perpetuate these stereotypes: peer pressure, mass media. (Paul 1998: 58)
\end{abstract}

While it seems easy for non-Arab children to learn and accept what they learn from Disney and Hollywood's negative stereotypes, it seems that things are more difficult for children from Arab descent to combat those stereotypes amongst some of their peers. Shaheen (2000) states, "Arab-American children have been subjected to physical and verbal harassment, and also have to endure stereotypes of the Arab and Islamic world that trickle down through children's books and cartoons;" worst still, "children have experienced humiliation and fear among their schoolmates and the climate of prejudice and hate only deepens the wound of discrimination" (Merskin 2004: 172). 
Certainly the comic vilification of Arabs in some animated movies has had continuous negative effects on Arabs, especially those living in the West, since "propaganda standardizes current ideas, hardens prevailing stereotypes, and furnishes thought patterns in all areas. Thus it codifies social, political, and moral standards" (Ellul 1969: 163). In view of that, some cartoon films about Arabs have adopted and adapted to different modes of comic representations whereby they can be able to translate Arab locations and people in humorous veins by classifying and depicting them according to the codes of Orientalist ${ }^{1}$ configurations. This kind of comic translation has allowed Arab locations and people to be apprehended by the cartoon viewers as frozen and raw materials liable to total conversion and imaginative transformation. Simply put, such comic translations constitute a way of perceiving the world that changes what the world is and what happens there to suit the tastes and agendas of the presenters. In support of this, one would argue that the worlds of animated cartoons transform territory and people, thereby making them fit the already existing Western views of the past, in which people and things are framed based upon funny and debased terms of exoticism.

As a case in point, Popeye the Sailor Meets Ali Baba and his Forty Thieves (1937) (Fleischer 1937) draws on both Arab folktales - including The Arabian Nights - as well as traditional Western notions about Arabs and the desert. This short animated movie features a host of common stereotypes of Arabs, including their portrayal as tricky schemers, avaricious villains and sorcerers, among many others. What is more intriguing about this animated cartoon is its usage of anecdotal features to represent the Arab people and land. The desert is pictured as barren and dangerous, and it is only populated with a bunch of stupid villains by the looks in their eyes and their always wide open mouths showing anecdotal features of missing teeth. This bunch of crazies is led by a sleazy bandit, Abu Hassan, and they can be found hanging around the Arab town continuously bent on terrorizing peaceful, funny looking hooked nose Arab civilians. Indeed, Popeye the Sailor Meets Ali Baba and his Forty Thieves (1937) draws an image of a desert that functions as a powerful symbol of a landscape existing outside of civilization (society/progress). The Arab land is populated with characters that best fit the imperial imagination of Europe. The clash between the Arab bandits and the Western heroes in the movie perfectly weaves an imperial scenario of two powers (evil vs. good), after which the good (apparently Western) ultimately triumphs and brings peace back to where it was.

Furthermore, Popeye the Sailor Meets Ali Baba and his Forty Thieves (1937) depicts the Arabian Sahara as an effectively, to use Henri Lefebvre's (1991) catchphrase, "dematerialized landscape" (Lefebvre 1991) provided with anecdotal topographies. The movie features some scenes of a tiny group of lined-up camels, and sometimes horses, made to move, jump or even act like they are dancing in a foolish manner at hearing the bandits (mostly drawn as stocky riders) sing. These Arab Bedouins are heading for an impoverished Arab town with dark and dirty streets where all sort of nasty things take place. Back to their caves, the bandits sing to their victorious day and the mass of wealth they now have, and again the lined up horses move up and down to the rhythm of the music.

One more intriguing aspect of the comic depictions of Arab characters in the Saharan space is the manner in which the villains are punished by the western heroes. Popeye is made a savior of Arabia when he tries to restore order. He saves the Arab men, children, and women from

\footnotetext{
${ }^{1}$ By the concept Orientalist, I draw upon Edward Said' (1978) designation of the term. For him, "anyone who teaches, writes about, or researches the Orient - and this applies whether the person is an anthropologist, sociologist, historian, or philologist - either in its specific or its general aspects, is an Orientalist, and what he or she does is Orientalism." (see Said 1978: 3)
} 
Abu Hassan and his bandits' evil wrath. This is, indeed, a construction of a perfect scenario for a benevolent war between the good and evil, the hero and the villain, after which the good (a Western hero and an avenging angel) always triumphs over the evil (a funny and bloodthirsty fool). In exemplifying this Western habit of constructing triumphant Western heroes as opposed to vanquished Arab villains, Popeye has come from far to rescue the women and children of Arabia from the tyrannical grip of the bandit Abu Hassan and his forty thieves. The evil side in this movie's narrative is an embodiment of a bunch of coward bandits set on terrorizing civilians, mainly helpless women, and wreaking havoc everywhere they go. By contrast, the good side personifies Popeye's, a Western character, bravery and heroism: these values have made him bridge the distance and instantly answer the call of duty - the Western duty or the white man's burden - towards uncivilized nations.

The retribution of the Arab characters, in this regard, is presented even in comical vein, as in the scene in which Popeye punches the bandits, one after another, thereby systematically causing them to fly back to their barrels with wide open mouths and missing teeth. The bandits are defeated so easily. Such comic defeat of the Arab villain (as if telling a joke worth laughing at rather than feeling sorry about it) certainly falls within the theoretical frames of Sigmund Freud's theory of the joke or when laughter becomes a sort of aggression. In this sense, Freud writes that,

Mankind have not been content to enjoy the comic where they have come upon it in their experience; they have also sought to bring it about intentionally, and we can learn more about the nature of the comic if we study the means which serve to make things comic. (Harper 2002: 2)

Quite interestingly, the conception of laughter has always been a challenging area of study owing to its being one of most sophisticated emotional expression of human beings. In her essay, Laughter and aggression: Desire and derision in a postcolonial context, Virginia Richter (2005) builds upon Freud's theory of laughter as an act of aggression to put forward the idea that the greatest pleasure one can get is often felt after playing jokes on others. These sorts of jokes are called "obscene or tendentious jokes." In appropriating pleasure to aggression, Richter posits that when something (e.g., culture, religion or language) or somebody (e.g., a member of an ethnic group) is the object of a joke, these jokes can be "subversive". That is to say, the joke no longer retains its fun aspects, but it becomes humiliating and seeks to symbolically vanquish the object of the joke. Therefore, in trying to uncover the comic aspects of the object being laughed at, one is, indeed, exposing oneself to its ominous repressed drives (Richter 2005: 63). Therefore, "jokes are based on the release of repressed sexual or aggressive impulses" (ibid.). In this sense, jokes are also described as,

Manifestations of a symbolic victory over an enemy, a victory that is confirmed by the laughter of the third person (the audience). By laughing, the hitherto indifferent listener is transformed into someone who shares the hate and contempt of the narrator for the object of the joke. In this way, a 'coalition' is formed between the first person (who tells the joke) and the third person (who listens and laughs) at the expense of the second person (the butt of the joke). Freud makes it abundantly clear that the primary impulse of the joke is not 'funny' but hostile, intended to humiliate and vanquish the 'enemy' (Freud: 98). In this constellation, the role of the third person is quite crucial: the listener is the authority who confirms the defeat of the butt, the triumph of the teller, and, consequently, the establishment of a hierarchical power structure. (Richter 2005: 63) 
It is by inflicting comic retributions upon the Arab villains that some animated movies further bond with their audience, thereby expressing their repressed contempt against their common Arab enemy. The laugh of the audience is proven to be a sign of the triumph of the movie producer over both the audience - for they have accepted to applaud to all that the animated movie presents them with - and the Arab villain - since some animated movies' producers believe that in laughing at Arabs, they "touch but their vanity, and [they] attack their most vulnerable part" (Watt 2002: 65). It is their feeling of being humans that is touched. Therefore, "let them see that they can be laughed at, you will make them angry" (ibid.). Comedy in general and jokes in particular perform quite surprising functions. That is to say,

Jokes often function as neuralgic points, as points at which the conventionally censored or repressed find expression, they are performing a permissible, indeed institutionalized, function. Thus, comedy in general, and the comic in particular, become, somewhat paradoxically perhaps, the appropriate site for the inappropriate, the proper place for indecorum, the field in which the unlikely is likely to occur. (Neale \& Krutnik 1990: 92)

Implicit in this quote is its stress on the unlikeliness of the comic. Jokes, for instance, perform inconsistent functions. For instance, in their dependence on comedy, some animated movies' producers leak their ideologies to audiences in unexpected ways. One of the animated cartoons' strange and intelligent forms of telling stories about Arabs in comic veins is their use of anachronistic humor. When unexpected events or artifacts happen to be placed in different epochs or settings than those where they are meant to exist, some animated movie producers intend to provoke the audience's hilarious laughter. An example of this kind of humor might be the everyday observation of how unintended anachronisms in animated films about Arabs become amusing in the eyes of later generations.

In Popeye the Sailor Meets Ali Baba and his Forty Thieves (1937), for example, it is easy to guess the historical epoch the movie intends to shoot, since it is so clearly disclosed by the clothing, the desert setting, the Arab trading gold currency or the use of camels, swords, and daggers, among many other features. When unexpected details are added to this historical epoch, some animated movie producers certainly intend (other than filling the desert land and thus laying hands over it) to provoke the audience's laughter and make their movies more entertaining and unexpectedly unique in their own right.

As examples of these additions, the movie inserts technologies which belong to present time, such as Gas stations, electric radios, a tank, the traffic lights in the middle of the desert and a sophisticated plane that can also function as a ship. In short, the movie blends stories from the Arabian Nights with modern Western artifacts so as to create a new space in the desert land. This space is certainly a place where audiences enjoy visiting and discovering in nonconformist and new ways, and upon which they keep laughing hilariously ever so much and frolic to their hearts.

Quite noticeable is the fact that in some animated movies, "anachronistic humour rarely projects modern-day phenomena directly onto the past: it more often tends to disrupt the harmony of the epoch by introducing elements from other historical contexts" (Salmi 2011: 17). This disruption caused by the insertion of unintended artifacts in other historical contexts is what makes of anachronistic humor a success and further contributes to the wide reception of animated films. In this sense, 
Anachronistic humour often relies on surprising juxtapositions. This comic impression has been explained by using a theory of degradation or psychological opposites, which argues that comic effect is produced by the appearance of something other than the expected result (for example, something small instead of massive or vice versa). The transgressing of boundaries between epochs can be seen as utilizing the idea of degradation: the filmmakers thwart expectations by bringing in unexpected historical elements, resulting in bathos for spectator amusement. (Salmi 2011: 19)

In fact, what makes anachronistic humor much of a success in animated movies is its ability to provoke different interpretations as to a certain scenic situation. The viewer tends to link the events seen on screen with those previously read or taught, and thereby come up with different interpretations of what the movie intends to transmit as messages. Importantly, the laughing element makes animated movies more interesting in that they try to render the whole scenes of a movie comic in tone so that audiences will not feel tired or bored while watching. More interestingly, anachronistic humor is more distinguishable in animated cartoons about Arabs than other movies about other races.

Consider, for instance, the animated movie of Ali Baba Bound (Clampett 1941) wherein its producer tries to insert some artifacts which do not belong to the desert land. For instance, the movie features different electric sign posts of Gas stations, the oasis and Soda Pop, among others. Taken to even a higher degree, the movie shoots camels as analogs of cars for rent, and they feed on gas fuel rather than grass. Camels are even holding sign posts that read, "Hump-mobile with 4 heels with gas/ Kiddy Kar. (ibid). In fact, introducing such modern features to a desert setting hints at the way the West has always thought about the East. More importantly, there is one very important feature adopted by the movie producer as regards Porky Pig. As is featured throughout the movie, this character is instilled with Western socalled ideals of defending the land and the weak (the example of coming to the rescue of baby dumping the camel). The humor based nature of anachronism here lies in its very adoption of a Western attitude of civilizing not only people but also animals.

Porky Pig is made a Western soldier defending the Western Fort in the desert. The very idea of using an animal as a replacement of a human character yields intriguing results. That is to say, dealing with the barbarity of Arabs residing in the desert entails the creation of a civilized animal that can better communicate with them since they are by nature thought to have animalistic features. The message here is that the West can tame and civilize animals that can possess later on human features whereas Arab humans of the desert can still be animals and act as ones. Therefore, we better use civilized animals when dealing with uncivilized Arab animals cloaked in human bodies. This is what anachronism intends to manifest in its adoption of using an animal character (Porky Pig) to further its dissemination of stereotypes about a people and their lands.

In fact, in both cartoons Ali Baba Bound (1941) and Popeye the Sailor Meets Ali Baba and his Forty Thieves (1937) the desert setting is subject to the "mission civilisatrice" of the West, thereby the desert is changing to something more of a Western idea. That is to say, the movies are far removed from the imagery of belly-dancers inside tents or the notorious image of the Arab sheikh being fed on grapes and drinking wine. Instead, the whole setting is being transformed into a more or less modern Western camp. Such move towards modernization is described in Edward Said's (1978) wording as a mission in which "the modern Orientalist was, in his view, a hero rescuing the Orient from the obscurity, alienation, and strangeness which he himself had properly distinguished" (1978: 121). 
Importantly, in its rescuing of the Orient, some animated cartoons have found relief in using anachronisms, since anachronistic humor can mean more than it tends to make us see. Therefore, "one of the most distinguishing features of humor is the way in which it forces us to shift our initial expectations, and this is true whether the source of the humor is a joke's punch-line or an unexpectedly comic situation" (Niebylski 2004: 12). Accordingly, shifting audience expectations is, in fact, a turning point wherein, at times, humor starts to be filtered through the lens of fear and, at other times, fear through humor. This situation results in confusion since audiences tend to reveal quite different reactions at separate moments during the watching of a movie: sometimes they laugh and other times they are scared. At this point, the boundaries between humor and fear become blurred. Stephen Hessel (2010) spells out this kind of audience oscillation between fear and laughter most clearly in his essay, Horrifying Quixote: The Thin Line between Fear and Laughter Hessel (2010) argues that people tend to project their social fears, worries and experiences onto a movie. He explains that:
All of these very real anxieties are tied in literature to infernal forces (corporeal) and spirits (incorporeal) that assault the systems of reason and piety. The existence of these proto-horror stories employs frightful narrative tools and personalities, but they most obviously lay bare the cause of the preoccupation itself; typically a preoccupation that comes from an aspect of a society in crisis. (2010: 27)

Sometimes some film scenes can be reminiscent of spectators' stories of fear that permeate their societies. This fear is a result of the many past atrocities and heinous crimes committed against innocent people on cyclical moments and in different parts of the world. There is also this fear that these crimes would continue for very long before it is noticed. Although both cartoon films analyzed here were produced in the very far past, still they both remind their audiences that there are moments tinged with fear that should never be forgotten, for fear that they may repeat themselves at any time, just like the myriad terrorist crimes we keep watching on everyday TV channels, and the blameworthy of which are always Arabs and Muslims. Therefore, people find relief in movies since they are sites upon which to contest their fears. Simply put, a movie about Arabs, for instance, projects them in threatening tones that perfectly fits the audience's pre-conceived perceptions and anxieties about them. This Arab threat is diminished once Arab terrorists commit stupid faults that bring about their funny end and eventually the audience's relief and serenity. A case in point is the cartoon of Popeye the Sailor Meets Ali Baba and his Forty Thieves (1937).

In this animated movie, Arabs are so stupid and foolish that their silliness can be the cause of their own destruction. Such a view coincides with a scene in the movie where the Arab bandits try to attack Popeye all at once while crying out in a cacophonous noise. However, the bandits and their chief Abu Hassan are so easily defeated and made to drag a huge cart full of stolen gold and jewels. At this juncture, the movie becomes comic and provides relief to the audience from their anxieties. The message the movie transmits here is that though Arabs are the source of fear and danger, they will eventually destroy themselves and become transformed into the butt of jokes of every movie and, more than that, even in reality, thereby allowing spectators to laugh at them hilariously.

In fact, this kind of construing a silly and comic Arab life through the Orientalist gaze hides a wealth of assumptions about the relationship of the representation to the real world. Such Orientalist imaging offers two central and interrelated illusions: that the "Orient" is utterly distinct from Europe - unaffected by European civilization - and that this Orient is frozen in time, more or less the same as it had been for hundreds of years. Therefore, the Arab subject 
who lives far away in the desert is funny, uncivilized, and is still living outside of history. Considerably, through using humor to appeal to many a spectator's cinematic tastes, animated cartoons about Arabs have indeed offered the Orientalist's eye a chance to penetrate the Arab geography and move along the streets to hysterically laugh and poke fun at the silly Arabs, drawing exotic images that appeal to the Western viewers.

Worse yet, by characterizing an entire region as barbaric and stupid, some animated movies cultivate an incredibly negative stereotype of Arab people that children will absorb and retain for generations. Still one very important point to keep in mind is the idea that this study draws its conclusion from the case study of two animated films produced in 1937 and 1941, without contemporary comparisons. The rationale underpinning such choice is that these films and their likes, produced around the same period of time, are a kind of reminder of spectators' stories of fear permeating their societies. This fear of something and anything is always there lurking in the dark behind walls or air jets awaiting for cowardly moments to make contemporary terroristic changes. Therefore, the idea here is not to draw a contemporary comparison, but rather to touch upon this idea of fear drawn from past experiences, and which may never have an end, at least in the film spectators' minds.

\section{References}

\section{FILMOGRAPHY}

Clampett, R. (Director). Ali Baba Bound, 1941. [Motion Picture].

Fleischer, M. (Director). Popeye the Sailor Meets Ali Baba and his Forty Thieves, 1937. [Motion Picture].

\section{BIBLIOGRAPHY}

Al-Nowaihi, Magda M. (2005) "The "Middle East"? Or.../ Arabic Literature and the Postcolonial Predicament." In Henry, Schwarz and Sangeeta, Ray (Eds.). A Companion to Postcolonial Studies. pp. 282-303. Malden: Blackwell Publishing Ltd. CrossRef

Bachelard, G. (1969) The Poetics of Reverie: Childhood, Language, and the Cosmos. Trans. Daniel, Russell. Boston: Beacon Press.

Bignell, J. (2000) Postmodern Media Culture. Edinburgh: Edinburgh University Press.

Curran, A. and Donelan, C. (2009) "Gender." In Paisley Livingston and Carl Plantinga (Eds.). The Routledge Companion to Philosophy and Film. New York: Routledge.

Curtis, S. (1994) "The Taste of a Nation: Training the Senses and Sensibility of Cinema Audiences in Imperial Germany." Film History 6(4) 445-469.

Ellul, J. (1969) Propaganda: The formation of Men's Attitudes. New York: Alfred A. Knopf.

Fuery, P. and Fuery, K. (2003) Visual Cultures and Critical Theory. London: Arnold.

Gere, C. (2010) "Slitting Open the Kantian Eye." In Chris Bailey and Hazel Gardiner (eds.) Revisualizing Visual Culture. pp. 151-164. Farnham and Burlington: Ashgate.

Harper, G. (Ed.) (2002) Comedy, Fantasy and Colonialism. London and New York: Continuum.

Hessel, S. (2010) "Horrifying Quixote: The Thin Line between Fear and Laughter." In Stephen Hessel and Michèle Huppert (eds.) Fear Itself: Reasoning the Unreasonable. pp. 23-44. Amsterdam, New York: Rodopi B.V. 
Jenkins, H. (1992) Textual Poachers. Television Fans \& Participatory Culture. New York and London: Routledge.

Lefebvre, H. (1991) The Production of Space. Trans. Donald Nicholson-Smith. Oxford: Basil Blackwell.

Merskin, D. (2004) "The Construction of Arabs as Enemies: Post-September 11 Discourse of George W. Bush." Mass Communication \& Society, 7(2) 157-175. CrossRef

Neale, S. and Krutnik, F. (1990) Popular Film and Television Comedy. London and New York: Routledge.

Niebylski, D. C. (2004) Humoring Resistance: Laughter and the Excessive Body in Contemporary Latin American Women's Fiction. Albany, NY: State University of New York Press.

Paul, A. M. (1998) "Where bias begins: The truth about stereotypes." Psychology Today, 31(3) 52-65.

Persson, P. (2003) Understanding Cinema. A Psychological Theory of Moving Imagery. New York: Cambridge University Press. CrossRef

Richter, V. (2005) "Laughter and Aggression: Desire and Derision in a Postcolonial Context." In Susanne Reichl and Mark Stein (Eds.) Cheeky Fictions: Laughter and the Postcolonial. pp. 61-72. Amsterdam - New York, NY: Rodopi B.V.

Salmi, H. (2011) "Introduction: The Mad History of the World." In Hannu Salmi (Ed.). Historical Comedy on Screen: Subverting History with Humour. pp. 7-30. Bristol, UK and Chicago, USA: Intellect.

Said, E. W. (1978) Orientalism. New York: Random House.

Shaheen, J. G. (2001) Reel bad Arabs: How Hollywood Vilifies a People. (Brooklyn, NY: Olive Branch Press.

Shaheen, J. G. (2000) "Hollywood's Muslim Arabs." The Muslim World, 90(1-2) 22-42. CrossRef

Stevenson, N. (2002) Understanding Media Cultures. Social Theory and Mass Communication. London: Sage Publications.

Watt, J. (2002) "James Morier and the Oriental Picaresque." In Graeme Harper (Ed.). Comedy, Fantasy and Colonialism. pp. 58-72. London, New York: Continuum. 